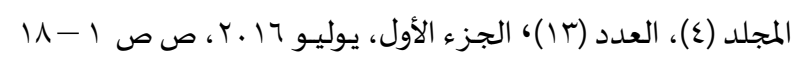

$$
\text { الألهح }
$$

$$
\begin{aligned}
& \text { إعداد } \\
& \text { د/ ناصر بن علي الموسىى } \\
& \text { عضو مجلس الثورى - رئيس مجلس إدارة جمعية } \\
& \text { المكفوفين الخيرية } \\
& \text { بمنطقة الرياض في المملكة العربية السعودية }
\end{aligned}
$$

DOI: $10.12816 / 0031872$ 


\section{ملخ م}

ظهرت برامج تعليم ذوي الاحتياجات الخاصـة في العالم العربي على مستوى المراحل الدراسية المختلفة، ابتداءً من مرحلة مـا قبل المدرسـة، ومروراً بمراحل التعليم العام (الابتدائي والمتوسط والثانوي)، ثم التعليم الجامعي والدراسـات العليا، وأخيراً التعليم المستمر والتعلم مدى الحياة، وتبعاً لذلك قامت بعض الجامعات العربية باستحداث أقسام للتربية الخاصـة تعنى بإعداد الكوادر البشرية المتخصصة في هذا النوع من التعليم، وتم إنشاء العديد من المراكز والجمعيات والهيئات والمؤسسـات التي تعنى بذوي الاحتياجات الخاصـة في القطاعات الحكوميـة والأهليـة والخيريـة، ويلاحظ أن هناك تفاوتاً واضحاً من بلد عربي لآخر ، وذلك وفقاً للظروف السياسية والاقتصادية والاجتماعية التي تعيشها البلدان العربية. وفي ظل هذا التوسع وذاك الانتشار لتلك الكيانات، برزت الحاجة الماسة إلى إيجاد مجلس عربي لتعليم ذوي الاحتياجات الخاصدة يشكل مرجعيـة تتولى رسـم السياسـة العامـة في مجـال تعليم ذوي الاحتياجـات الخاصـة على مسـتىى العالم العربي، وتقوم بعملية التعاون والتتسيق والتكامل بين الكيانات المختلفة، وتضع الضوابط والمعايير العلمية التي بموجبها يتم منح شهادات الترخيص لهذه المؤسسات والمراكز والبرامج، بالإضـافة إلى إعداد واستخدام الآليات الضـرورية للإشـراف عليها وتقويمها ومتابعتها، وكذلك إيجاد الحوافز المادية والمعنوية للمتميز منها، واتخاذ التدابير اللازمة لإصلاح أوضاع تلك التي يقل أداؤها عن الحد الأدنى في تقديم الخدمات لذوي الاحتياجات الخاصة. الكلمات المفتاحية : المجلس العربي - ذوى الاحتياجات الخاصة. 


\section{Arab Council for Education of Students with Special Needs}

\section{Dr. Nasser bin Ali Al-Mosa ${ }^{\left({ }^{*}\right)}$}

\section{Abstract}

Programs for the education of students with special needs have been spreading in the Arab world through different educational levels, beginning from preschool, up to public education (elementary, middle, and secondary), through higher education programs, and finally continuing and lifelong education. According to this, some Arab universities have established new Special Education Departments to prepare specialists in this type of education.

A lot of centers, associations, and organizations have been established to provide care for individuals with special needs in public, privet, and charitable sectors.

It is clear that there is a great variation in the scope and type of services provided in special education.

As a result, there is an urgent need for the establishment of an Arab council for the education of students with special needs.

This Council will play the role of making public policies in the field of special needs education, throughout the Arab world.

This is to achieve the cooperation, coordination, and integration among different entities in the region.

This council will provide scientific standards related to the credentials of these centers and programs, in addition to the preparation of the necessary mechanisms for the supervision and evaluation of these centers.

It well, also give material and incentives for the distinguished ones, and take the necessary precautions for repairing the conditions of those that do not provide the needed services for people with special needs.

Key words: Arab Council for Education of- Students with Special Needs

$\left(^{*}\right)$ Member of consultative council/president of the blind Association in Riyadh - Kingdom of Saudi Arabia.

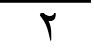


ظهرت برامج تعليم ذوي الاحتياجات الخاصـة في العالم العربي على مستوى المراحل الدراسية المختلفة، ابتداءً من مرحلة مـا قبل المدرسة، ومروراً بمراحل التعليم العام (الابتدائي والمتوسط والثانوي)، ثم التعليم الجامعي والدراسات العليا، وأخيراً التعليم المستمر والتعلم مدى بهى الحياة، وتبعاً لذلك قامت بعض الجامعات العربية باستحداث أقسام للتربية الخاصة تعنى بإعداد الكوادر البشرية المتخصصة في هذا النوع من التعليم، وتم إنشاء العديد من المراكز والجمعيات والهيئات والمؤسسات التي تعنى بذوي الاحتياجات الخاصـة في القطاعات الحكوميـة والأهلية

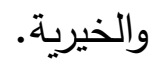

وتختلف البدايات التاريخية لبرامج وخدمات تعليم ذوي الاحتياجات الخاصـة في العالم

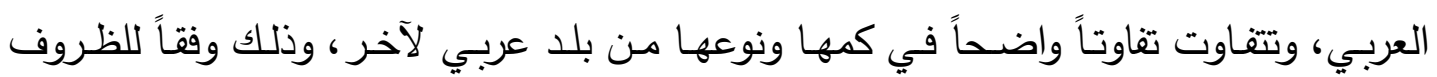
السياسية والاقتصادية والاجتماعية التي تعيشها البلدان العربية. وفي ظل هذا التوسع وذاك الانتشار لتلك الكيانات، برزت الحاجة الماسـة إلى إيجاد مجلس عربي لتعليم ذوي الاحتياجات الخاصـة يشكل مرجعيـة تتولى رسم السياسـة العامـة في مجـال تعليم ذوي الاحتياجـات الخاصــة على مستوى العـالم العربـي، وتقوم بعمليـة التعـاون والتتسيق والتكامل بين الكيانات المختلفة، وتضع الضوابط والمعايير العلمية التي بموجبها يتت منح شـهادات الترخيص لهذه المؤسسـات والمراكز والبرامج، بالإضـافة إلى إعداد واستخدام الآليات الضرورية للإثراف عليها وتقويمها ومتابعتها، وكذلك إيجاد الحوافز المادية والمعنوية للمتميز منها، واتخاذ التدابير اللازمة لإصداح أوضاع تلك التي يقل أداؤها عن الحد الأدنى في وسي تقديم الخدمات لذوي الاحتياجات الخاصة.

\section{وسوف يتركز النقاش في هذه الورقة على المحاور الرئيسة التالية:}

1- الإطار المفاهيمي للمجلس العربي لتعليم ذوي الاحتياجات الخاصة. r- الأسس والمبادئ والمرتكزات والمنطلقات التي تقوم عليها فلسفته. r- الأهداف التي يرمي إلى تحقيقها. 


$$
\begin{aligned}
& \text { ع- الصلاحيات التي ينبغي أن يتمتع بها. } \\
& \text { 0- المهام التي يفترض أن يقوم بها. } \\
& \text { 7- دوافع إنشاء المجلس. } \\
& \text { V- التظيم الهيكلي للمجل. } \\
& \text { 1- طريقة تشكيل المجلس. } \\
& \text { 9- التبعية الإدارية للمجلس. } \\
& \text { • 1- مصادر تمويل المجلس. } \\
& \text { 11 آليات عمل المجلس. } \\
& \text { r ا - النظام الأساسي للمجلس. }
\end{aligned}
$$

هذا، بالإضافة إلى مناقشة بعض القضايا الأخرى المتعلقة بهذا الموضوع، واستعراض مقترح يقضي بإقامة ملتقى علمي ينظمه المجلس العربي بشكل دوري.

$$
\text { أولًا : الإطار المفاهيدي للمجلس العربي لتعليم ذوي الاحتياجات الخاصنة: }
$$

يقوم المجلس العربي على مفهوم شامل، وذلك من خلال استخدام مصطلح: "تعليم ذوي الاحتياجات الخاصـة" (Special Needs Education) بدلاً من مصطلح: "التربية الخاصـة" (Students with أو مصطلح "الطـلاب ذوي الإعـاقة")، (Special Education) Disabilities) الخاصة فحسب، ولا على تعليم ذوي الإعاقة فقط، وإنما يمتد بخدماته ليشمل الأطفال في برامج التعليم المبكر، أي تعليم مـا قبل المدرسـة، وهو الذي يبدأ من سن الميلاد حتى سن السادسـة، والتلاميذ والتلميذات في برامج التربية الخاصـة بالتعليم العام ومعاهد التربية الخاصـة، والطلاب والطالبـات ذوي الاحتياجـات الخاصـة في بـرامج التعلـيم العـالي، والطـلاب والطالبـات ذوي الاحتياجات الخاصـة في برامج التعليم الفني، والدارسين والدارسـات ذوي الاحتياجات الخاصـة في برامج التعليم المستمر والتعلم مدى الحياة. 
والطلاب والطالبات ذوو الاحتياجات الخاصة الذين يستهفهم هذا النوع من التعليم هم الذين يختلفون عـن أقـرانهم العـاديين إمـا في قدراتهم العقليـة، أو الحسـية، أو الجسـية، أو الأكاديمية، أو التواصلية، أو السلوكية والانفعالية اختلافاً يوجب تقديم خدمات تعليمية إضافية. وفي الإطار المفاهيمي لتعليم ذوي الاحتياجات الخاصـة، فإن الفئات الخاصـة، وذوي الاحتياجات الخاصة، والطلاب غير العاديين، والطلاب الاستثنائيين هي مصطلحات متقاربة في معناها، وغالباً مـا تستخدم على اعتبار أنها مصطلحات مترادفة، وهي تستهدف الطلاب والطالبات ذوي المواهب من العاديين، والطلاب والطالبات ذوي الإعاقات، وغيرهم من الطلاب والطالبات الذين قد يحتاجون إلى خدمات تعليمية إضافية. وهذه الخدمات التعليمية الإضـافية هي التي تقوم عليها برامج تعليم ذوي الاحتياجات الخاصة، وتتضمن برامج التدخل المبكر ، وبرامج التربية الخاصة، وبرامج التعليم العالي، وبرامج التعليم الفني، وبرامج التعليم المستمر والتعلم مدى الحياة. ثانياً: الأسس و المبادئ والدنطلقات والمرتكزات: 1- يُشرِّع دينتا الإسـلامي الحنيف وأن طلب العلم فرض على كلى كل فرد بحكم الإسـلام، وأن نشر العلم وتيسيره في المراحل المختلفة واجب على الدول بقدر وسعها وإمكانياتها. r- تتص الأنظمة والتشريعات في العالم العربي على أن الدول تكفل الحق في التعليم لذوي الاحتياجات الخاصة حسب خصائصهم واحتياجاتهم. r- تؤكد وثائق سياسـات التعليم في العـالم العربي على أن الدول معنيـة باكتثـاف ذوي الاحتياجات الخاصة، وتوفير البرامج والخدمات والنشاطات التعليمية لهم على اختلاف

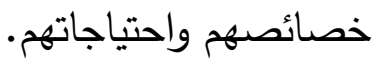
ع - تطالب المواثيق والمعاهدات والاتفاقيات العالمية بضرورة توفير التعليم المجاني المناسب لذوي الاحتياجات الخاصة بما يلبي احتياجاتهم ويحقق طموحاتهم. ه- تظهـر الأبحـاث والدراسـات أن ذوي الاحتياجـات الخاصـة على اختلاف خصائصـهم واحتياجاتهم قابلون للتعلم على تفاوت واضح في كم ونوع هذا التعليم. 
ج- تبـين التجـارب والخبـرات أن وجـود المرجعيـات يـؤدي إلى التعـاون والتنسيق والتكامـل،

وتوحيد الجهود وتكثيفها، وتلافي الازدواجيـة التي هي ضـرب من ضـروب الهدر في

$$
\text { الوقت والجهد والمال. }
$$

V- تشـير تـداولات المؤتمرات والمنتديات العلميـة إلى أن الاهتمـام بتعليم ذوي الاحتياجـات الخاصة يعد مدخلاً أساساً من مداخل إصلاح التعليم بشكل عام.

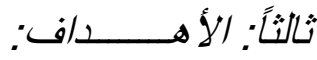

يهدف هذا المجلس - بشكل عام - إلى الارتقاء بمستوى كم ونوع البرامج والخدمات

والنشـاطات المقدمـة لذوي الاحتياجـات الخاصـة على مستوى العـالم العربي بمـا ينسـم وأحدث التوجهات والتطورات العالمية في مجال تعليم ذوي الاحتياجات الخاصـة، ويواكب أهم التطلعات والمتطلبات الميدانية في العالم العربي.

$$
\text { رابعاً: الصــــالحهبـات: }
$$

يتمتـع هـذا المجلس بكافـة الصـلاحيات التي تمكنـهـ مـن القيـام بمهامـه على الوجـهـ

$$
\text { خامساً: المهــــــام: }
$$

ا - تطوير السياسـات والاستراتيجيات في مجال تعليم ذوي الاحتياجـات الخاصـة على مستوى

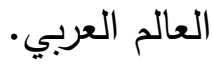

ץ- التواصـل والتعـاون والتتسـيق والتكامـل بين الهيئات والمؤسسـات الحكوميـة وغير الحكوميـة العاملة في المجالات ذات العلاقة بتعليم ذوي الاحتياجات الخاصة. ب-تبادل التجارب والخبرات والأطروحات والأفكار والرؤى في مجال تعليم ذوي الاحتياجـات الخاصة بالعالم العربي. ع - العمل على التوسع في برامج الكثف والتدخل المبكر والدمج التربوي. 
ه-دعوة مؤسسات التعليم العالي في العالم العربي إلى مراجعة برامجها وخططها الدراسية بما ينسجم مع متطلبات الدمج التربوي، ويحقق مبادئ التعليم الثامل، والعمل على استحداث أقسام وشعب للتربية الخاصة على المستوى الجامعي والدراسات العليا.

1-دعم وتنشـيط حركـة البحـث العلمي والنشـر في مجـال تعليم ذوي الاحتياجـات الخاصـة، والتعـاون مـع الجمعيـات المتخصصــة والجامعـات ومراكز البحـث العلدي في إجـراء الدراسات التخصصية والميدانية.

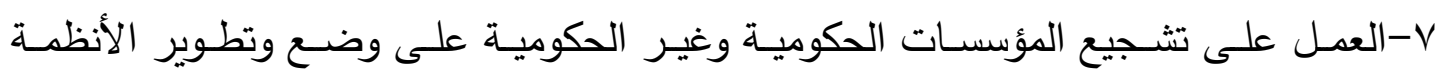

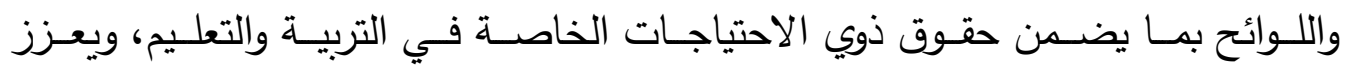

مشاركاتهم واندماجهم في المجتمع، ومتابعة تفعيلها.

^- حث المؤسسات التعليمية ومؤسسات التعليم العالي في العالم العربي على تضمين مفاهيم تربية وتعليم ذوي الاحتياجات الخاصـة في المناهج الدراسية ضمن إطار الدمج التربوي

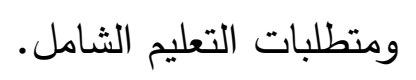

9-العمل على تفعيل الدور المستقبلي لمعاهد ومراكز التربية الخاصـة بما ينسجم مع متطلبات

$$
\text { الدمج التربوي. }
$$

• 1- اقتراح المعايير اللازمـة لبرامج إعداد وتدريب الكوادر البشرية في مجال تعليم ذوي

$$
\text { الاحتياجات الخاصة وتقويمها. }
$$

1 1 - التأكيد على أهمية تقويم البرامج والخدمات التربوية المقدمة لذوي الاحتياجات الخاصة في

$$
\text { العالم العربي. }
$$

r ا - التأكيد على أهمية تطوير عملية التقويم والتشخيص في العالم العربي من خـلا إعداد

$$
\text { وتطوير وتقنين الأدوات المناسبة. }
$$

با - العمل على تتظيم المؤتمرات والندوات والملتقيات العلمية بما يرقى بالمستوى المهني لدى

$$
\text { العاملين والعاملات في مجال تعليم ذوي الاحتياجات الخاصة. }
$$

ع ا- العمل على توفير البرامج التدريبية اللازمة لتتمية الكوادر البشرية المتخصصة. 
1 - العمل على تفعيل دور أولياء الأمور في مجالات تعليم ذوي الاحتياجات الخاصة. 7 ا - تشجيع العمل التطوعي في مجال تعليم ذوي الاحتياجات الخاصـة، والعمل على تأصيل مفهومه، ونشر ثقافته بين العاملين والعاملات في هذا القطاع.

IV - تشجيع القطاع الخاص على التوسع في تقديم خدمات تعليم ذوي الاحتياجات الخاصة. 1 ا - العمل على تفعيل دور الإعلام بنوعيه الجديد والتقليدي من خلال وسائله ومنابره المختلفة في سبيل تغيير الاتجاهات والمواقف السلبية تجاه ذوي الاحتياجات الخاصـة في العالم العربي•

9 ( - توفير قاعدة معلومات عن برامج تعليم ذوي الاحتياجات الخاصـة، والعاملين فيها، والفئات

المستفيدة منها، وعن الأبحاث والدراسات والوثائق المتعلقة بها. • ץ- تفعيل مواقع تعليم ذوي الاحتياجات الخاصـة على الشبكة العالمية للمعلومات (الإنترنت)، وربطها ببعضها البعض بهدف تسهيل تبادل المعلومات. ا T - ما يقره المجلس من مهام أخرى. سادساً: دوافع إنشاء المجلس:

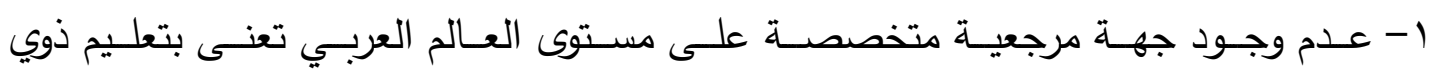
الاحتياجات الخاصة بما يضمن حقوقهم، ويلبي احتياجاتهم، ويحقق طموحاتهم. ץ-وجود تحدٍ كبير يواجه تعليم ذوي الاحتياجات الخاصـة في العالم العربي، يتمثل في مشكلة ذات بعدين؛ بُعد كمي، حيث تشير الإحصاءات العالمية إلى أن حوالي · ب ٪ من إجمالي طلاب وطالبات مدارس التعليم العام في أي بلد من بلدان العالم قد يحتاجون إلى خدمات التربيـة الخاصـة، في حين تشـير الإحصـاءات العربيـة إلى أن نسبة المستقيدين مـن هـهـ الخدمات في العالم العربي لا تتجاوز ه ٪ من إجمالي المستهدفين، وبُعد نوعي، إذ يبلغ عدد فئـات ذوي الاحتياجـات الخاصـة المحتاجـة إلى خدمات التربيـة الخاصـة إحدى عشـرة فئسة حسب تصنيف الأسرة الوطنية للتربية الخاصة بوزارة التعليم في المملكة العربية السعودية. 
r- تعثر قبول كثير من الفئات الخاصة في برامج مؤسسات التعليم العالي، وعدم تهيئة كثير من البيئات الجامعية لصالح هذه الفئات.

ع- البطء الواضح في النمو الكمي والتطور النوعي، وعدم الثبات في مستوى الخدمات التربوية

والتعليمية التي تقدمها وزارات التربية والتعليم في العالم العربي لذوي الاحتياجات الخاصة. 0- القصور الثديد الذي يصل إلى حالة العدم في برامج التدخل المبكر ، رغم أهميتها البالغة،

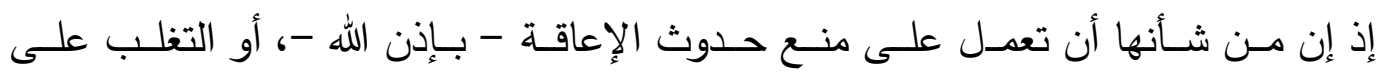
مشكلتها، أو الحد من آثارها النفسية والاجتماعية والاقتصادية على الأسرة والمجتمع. 1- تطور دور ذوي الاحتياجـات الخاصـة وذويهـم في المطالبـة بحقوقهم التربويـة والتعليميـة، ومناشداتهم المستمرة في الحصول على هذه الحقوق على أرقى المستويات. V- إن التكلفة الاقتصادية لإنشاء هذا المجلس، وما ينجم عن ذلك من برامج وخدمات تقدمها أنظمة التعليم في العالم العربي كحقوق مشروعة لذوي الاحتياجات الخاصة لا تساوي شيئًا في مقابل النتائج المرجوة التي ستعمل - بإذن الله تعالى - على زيـادة أعداد المتعلمين

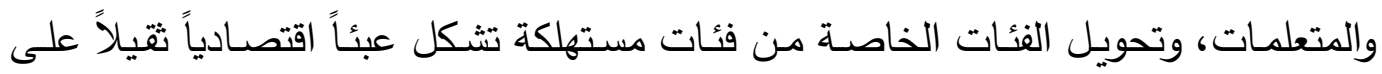
المجتمع إلى فئات منتجـة تسهم - بشكل فاعل - في خدمة الوطن العربي ورقيه وتقدمـاه

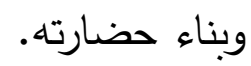
سابعاً: التنظيم الهيكلي للمجلس: يتكون المجلس من ثلاث وحدات رئيسة هي: أ) الجمعية العمومية.

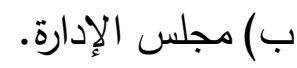
ج) المكتب التنفيذي. ثامناً: طريقة تشكيل الدجلس: 1- تتكون الجمعية العمومية للمجلس من كافة الأعضاء العاملين سواء كانوا أفراداً أو مؤسسات في مجال تعليم ذوي الاحتياجات الخاصة بالعالم العربي. 
ץ- تقدم كل دولة عربية مرشحيها ومرشحاتها من خلال الجمعيـة العمومية التي تقوم بانتخاب مرشـح واحد أو مرشحة واحدة لكل دولـة لعضوية مجلس الإدارة، وهو الذي يحصل على أعلى الأصوات في مجموعته.

ب- يقوم مجلس الإدارة في أول اجتماع لـه بانتخـاب رئيس، ونائب رئيس، وأمين عام، وأمين صندوق. ع - يكون مقر المكتب التنفيذي في البلد التي ينتخب منها رئيس المجلس. تاسعاً: التبعية الإدارية للمجلس: يتبـع هـا المجلس إداريـاً لجامعـة الـدول العربيـة، أو المنظمـة العربيـة للتربيـة والعلـوم والثقافة، أو قد يكون مستقلاً بذاته. عاشرًا: مصادر تمويل المجلس: ا- الدعم الحكومي الذي قد يحصل عليه المجلس من الحكومات العربية. ץ- الأوقاف والوصايا والهبات والتبرعات التي يحصل عليها المجلس. ب- المبـالغ التي يحصـل عليها المجلس مقابـل الأبحاث والدراسـات التي يقوم بهـا، والخطط والاستراتيجيات التي يعدها، والخبرات والاستشارات التي يقدمها. ع- رسوم اشتراكات العضوية في المجلس. حادي عشر: آلبات عمل المجلس: سيقوم المجلس بإعداد خطـة استراتيجية لعمله تتضـمن الرؤيـة والرسـالة والقيم والأهداف

$$
\text { وآليات العمل والأطر الزمنية. }
$$
يـتم تشـكيل فريـق تأسيسـي يتـولى مهــة إعـداد النظـام الأساسـي للمجـس، ويقـوم بالتحضيرات اللازمة لاستكمال إنشائه، وذلك وفقاً للتصور الذي اشتملت عليه هذه الورقة. 


$$
\text { الملتقى العلمي للمجلس العربي }
$$

يقوم المجلس العربي عند إنشائه بإقامة ملتقى علمي بشكل دوري، وذلك على النحو

أولاً: راعي الملتقى أحد أعيان الدولة المضيفة. ثانياً: طبيعة الملتقى: ا - يعد الملتقى علمياً في أساسـه، بالإضـافة إلى اشتماله على ورش عمل تدريبية، ومعارض تعريفية، وأنشطة توعوية وتواصلية. r- يقام الملتقى بشكل سنوي بالتتاوب بين الدول العربية. ثالثاً: موضو ع الملتقى: يـتم تحديـده بشـكل سـنوي، ويركـز على قضى قضـايا تعلـيم ذوي الاحتياجـات الخاصــة

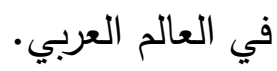
رابعاً: الجهة المنظمة: المجلس العربـي لتعليم ذوي الاحتياجـات الخاصـة بالتعـاون مـع واحدة أو أكثر مـن المؤسسات العلمية أو مؤسسات المجتمع المدني في الدولة المضيفة. خامساً: المكان و الزمان: - (الز ا- المكان: إحدى المدن في الدولة المضيفة. r- الزمان: في شهر إبريل من كل عام. r- المدة: أربعة أيام بما في ذلك حفل الافتتاح. سادساً: لغة الملتقى: العربية والإنجليزية.

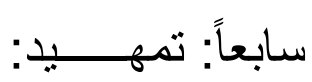
في إطار جهوده الراميـة إلى رفع الوعي بذوي الاحتياجات الخاصـة في العالم العربي، والارتقاء بمستوى كم ونوع البرامج والخدمات المقدمـة لهم، يتبنى المجلس العربي لتعليم ذوي 
الاحتياجـات الخاصـة فكرة عقد ملتقى علمي سنوي يتم تتظيمـه - بشكل تتـاوبي - بين الدول العربيـة، ويلتقـي فيـه ذوو الاحتياجـات الخاصــة وأوليـاء أمـورهم والعـاملون معهم والمختصـون والمهتمون في مجالات تعليم ذوي الاحتياجات الخاصة.

ومن المتوقـع أن يصبح هذا الملتقى جزيءاً مـن منظومـة العمل في مجـال تعليم ذوي

الاحتياجات الخاصـة، ومحفلاً علمياً مهماً يطوق إليه أبناء الوطن العربي، ومنبراً يتبادلون من خلاله الأفكار والرؤى والتجارب والخبرات، والاطلاع على أحدث التوجهات العالمية، والتعرف على أهم الاحتياجـات والمتطلبـات الميدانيـة في مجال تعليم ودعم ذوي الاحتياجات الخاصـة بالعالم العربي. ثنامناً: الأهداف العامة للملتقى: ا - تسـليط الضــوه علـى تعلـيم ذوي الاحتياجـات الخاصــة فـي العـالم العربـي، والتعريــف بخصائصهم واحتياجاتهم. ץ- التعريف بالبرامج والخدمات المقدمة للطلاب والطالبات ذوي الاحتياجات الخاصـة في العالم العربي، والعمل على تقويمها بغرض الارتقاء بمستواها كماً ونوعاً. ب- تفعيل دور البحث العلمي في مجال ذوي الاحتياجـات الخاصـة باعتباره أهم الوسـائل التي يمكن توظيفها في سبيل النهوض بتعليم ذوي الاحتياجات الخاصة في العالم العربي. ع - توظيف التقنية الحديثة لصالح ذوي الاحتياجات الخاصة في العالم العربي من أجل تمكينهم من أن يصبحوا أعضاء عاملين فاعلين في مجتمعاتهم. ه- استعراض أهم المستجدات في مجال تعليم ذوي الاحتياجات الخاصة محلياً وإقليمياً وعالمياً. ج- دراسـة سبل ووسـائل تفعيل الأنظمـة والقوانين والتشـريعات المعنيـة بتعليم ذوي الاحتياجـات الخاصة في العالم العربي. V- دراسـة طرق وأسـاليب تطوير البيئات الحياتيـة كالأسـرة والمدرسـة والمجتمع بشكل عام مـن أجل تمكين الطـلاب والطالبـات ذوي الاحتياجـات الخاصـة مـن التغلب على المشكلات والتحديات التي تواجههم في البيئات التعليمية بالعالم العربي. 
1- إقامة ورش عمل تدريبية تستهدف ذوي الاحتياجات الخاصة وأولياء أمورهم والعاملين معهم. 9- تتظيم نشاطات وفعاليات تستهدف ذوي الاحتياجات الخاصة وأسرهم. • 1- إقامة معارض مصاحبة تهدف إلى التعريف بالكتب والأبحاث والدراسـات المعنية بتعليم ذوي الاحتياجات الخاصة، وكذلك التعريف بالأدوات والأجهزة التعويضية. 1 1ا-دراسـة عوامل تعزيز دور المؤسسات والمنظمات والهيئات والجمعيات الحكومية والأهلية والخيرية المعنية بتعليم ذوي الاحتياجات الخاصة في العالم العربي. r ا - مناقشة أهم التحديات التي تواجه مجال تعليم ذوي الاحتياجات الخاصة في العالم العربي، وإيجاد الوسائل والأساليب الكفيلة بالتعامل معها. rا - تبادل الأفكار والرؤى والتجارب والخبرات في مجال تعليم ذوي الاحتياجات الخاصة بالعالم العربي. ع ا - العهـل على وضــع اسـتراتيجيات عربيــة متكاملــة للتعامـل مـع الطـلاب والطالبـات ذوي الاحتياجات الخاصة، وإيجاد الأطر العلمية والعملية الكفيلة بتفعيلها. 10 - العمل على بناء جسور التواصل والتكامل بين الدول العربية في مجالات تعليم ودعم ذوي

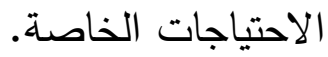
تاسعاً: الأهداف الخاصة للملتقى: يتم تحديدها بناء على تحديد موضوعات الملتقيات العلمية. عاشتراً: المشـــاركـــــن يشارك في الملتقى بإلقاء المحاضرات، وتقديم الأبحاث، وأوراق العمل، وورش العمل نخبة من الأكاديميين والباحثين والمعنيين والمهتمين في مجالات تعليم ذوي الاحتياجات الخاصة. حادي عشر: الفئات المستهدفة: يستهدف الملتقى عدداً من الفئات هي كالتالي: الماتهة 1- الطلاب والطالبات ذوو الاحتياجات الخاصة وأولياء أمورهم. r- العاملون والعاملات في مجالات ذوي الاحتياجات الخاصة. 
ب- أعضاء هيئة التدريس وطلاب وطالبات الأقسام المعنية بالكليات والجامعات العربية. ع - المهتمون والمهتمات، والمعنيون والمعنيات، وأصحاب العلاقة بذوي الاحتياجات الخاصة.

ثاني عثر : الأنشطة و الفعاليات: يصاحب الملتقى الأنشطة والفعاليات التالية:

ا- العديد من ورش العمل التدربية في مجالات تعليم ذوي الاحتياجات الخاصة. ץ- عقد العديد من الندوات واللقاءات التي يتمكن من خلالها المشـاركون في الملتقى من تبادل الآراء والخبرات، وطرح الأفكار والمبتكرات. r- تنظيم العديد من النشاطات والفعاليات لذوي الاحتياجات الخاصة. ع - يصـاحب الملتقـى معرضــان أحـدهما للكتـب والدراسـات والأبحـاث المتعلقـة بتعلـيم ذوي الاحتياجات الخاصة، والثاني للتجهيزات والوسائل المختلفة. ثالث عثر : طريقة تتظيم الملتقى: يتولى المجلس العربي لتعليم ذوي الاحتياجات الخاصـة الإشراف على الجانب العلمي للملتقى، وذلك من خلال تشكيل لجنة علمية في المجلس تقوم بالمهام التالية: 1- اختيار موضوع الملتقى في كل عام، وتحديد أهدافه ومحاوره وفعالياته. ץ- وضع الضوابط العامة لأوراق الععل والدراسات والأبحاث التي تقدم للملتقى، وتحديد الأطر الزمنيـة اللازمـة لـلك مثل: موعد استلام الملخصـات، وموعد استلام كامل أوراق العمل والأبحاث. r- اقتراح الأسماء المرشح استكتابها عند الحاجة. ع - دراسـة وتحكيم أوراق العمل المقدمة، والأبحاث والدراسات، وورش العمل، واختيار الأنسب منها. 0- إعداد كتيب الملخصات وكتاب الملتقى. 7- وضع البرنامج العلمي والزمني لجلسات الملتقى. V - اختيار رؤساء ومقرري جلسات الملتقى. 
فـي حسين تـــولى الدولــة المضــيفة الجوانـب التنظيميـة والإجرائيـة، وذلـك مـن

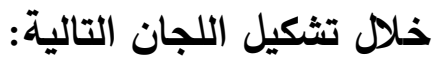

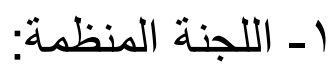

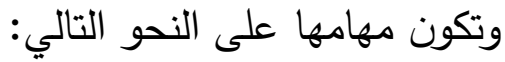

أ) الإشراف العام على سير أعمال الملتقى.

ب) إقرار الإطار العام للملتقى.

ج) إقرار قوائم أسماء المدعوين لحفل الافتتاح.

د) الاطلاع على تقارير اللجان واعتمادها.

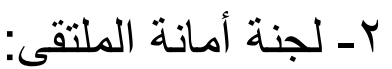

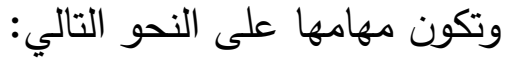

أ) اقتراح اللجان العاملة في الملتقى ومهماتها، وترشيح أعضائها.

ب) متابعة اللجان العاملة، وتقديم التقارير اللازمة للجنة المنظمة.

ج) استلام بريد الملتقى وعمل ما يلزم.

د) إعداد المخاطبات الخاصة بالملتقى.

هـ) استخراج تأثيرات الدخول للمشاركين عند الحاجة.

و) ما يسند إليها من مهام أخرى من قبل اللجنة المنظمة.

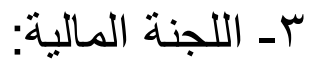

وتكون مهامها على النحو التالي:

أ) أبحث عن ممولين للملتقى.

ب) تولي مهام الصرف على الملتقى.

ج) إعداد تقرير أسبوعي وتقديمه للجنة المنظمة.

د) ما يسند إليها من مهام أخرى من قبل اللجنة المنظمة. 
ع ـ لجنة العلاقات العامة:

وتكون مهامها على النحو التالي:

أ) تنفيذ جدول الرحلات، وزمن وصول الضيوف والمشاركين.

ب) تهيئة مكتب لاستقبال الضيوف والمشاركين في المطار ، وتسهيل أمورهم. ج) استقبال كافة الضيوف والمشاركين. د) عداد جميع الترتيبات الخاصة بسكن الضيوف والمشاركين. ه) الإشراف على الوجبات والضيافة والمواصلات.

و) إعداد جدول زيارات المشاركين للأماكن المقرر زيارتها. ز) إعداد تقرير أسبوعي وتقديمه للجنة المنظمة. ح) ما يسند إليها من مهام أخرى من قبل اللجنة المنظمة. ـ ـ لجنة التسجيل و إخر اج الفعاليات: وتكون مهامها على النحو التالي:

أ) أمين الحقائب والأدوات القرطاسية اللازمة، وتوزيعها على المشاركين. ب) التسيق مع اللجان الأخرى حول محتويات الحقائب المطلوب إضافتها. ج) تســيل المشـاركين والحضـور ، وعمـل بطاقـات تعريغيـة بأعضـاء اللجـان والمشــاركين والحضور

د) تصميم شهادات الحضور والمشاركين، وتوزيعها. ه) وضع اللافتات التعريفية داخل مقر الملتقى. و) متابعة استكمال التجهيزات الخاصة بمقر الملتقى. ز) طباعة أو تصوير كتيب ملخصات أوراق الملتقى. ح) وضع اللافتات الإرشادية في الأماكن المخصصة لها، وإزالتها بعد نهاية الملتقى. ط) إعداد تقرير أسبوعي وتقديمه للجنة المنظمة. ي) ما يسند إليها من مهام أخرى من قبل اللجنة المنظمة. 


$$
\text { وتكون مهامها على النحو التالي: }
$$

أ) التغطية الإعلامية لفعاليات الملتقى.

ب) إعداد بطاقات الدعوات لحفل الافتتاح وتوزيعها.

$$
\text { ج) إصدار رسالة يومية عن فعاليات الملتقى. }
$$

د) تزويد موقع المجلس العربي لتعليم ذوي الاحتياجات الخاصة وموقع الجهة المستضيفة

على الإنترنت بالمستجدات الإعلامية عن الملتقى.

$$
\text { هـ) إعداد الخطابات لوسائل الإعلام. }
$$

و) إعداد تقرير أسبوعي وتقديمه للجنة المنظمة.

ز) ما يسند إليها من مهام أخرى من قبل اللجنة المنظمة.

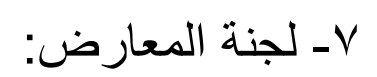

وتكون مهمتها: تتفيذ وإخراج المعارض المصاحبة للملتقى سواء بنفسها أو من خـلال

$$
\text { شركة متخصصة في هذا المجال. }
$$

$$
\text { رابع عشر: الجوانب الإجرائية: }
$$

1- رسوم المشاركة في الملتقى قد يكون من المناسب تحديد رسوم رمزيـة للمشاركة في المي الملتقىى، وخاصـة ورش العمل التدريبيـة، وتكون لصـالح المجلس العربـي لتعليم ذوي

$$
\text { الاحتياجات الخاصة بالاتفاق مع الدولة المضيفة. }
$$

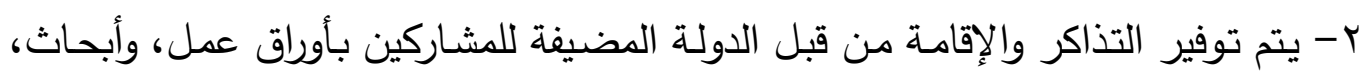

$$
\text { r- ورش عمل في حاذج مرفقة: }
$$

أ) - أستمارة مشاركة.

ب) نموذج أسعار الفنادق في الدولة المضيفة. 


\section{ج) استمارة حجز غرف.}

خامس عشر: الميز/نية المقترحة للملتقى:

تقدر ميزانية الملتقى بمبلغ ( . . . . . ب) دولار أمريكي، (مئتي ألف دولار أمريكي)، يتت

توفيرها من خلال الرعاة الرسميين للملتقى والجهات ذات العلاقة بذوي الاحتياجات الخاصـة في

الدولة المضيفة. 